\title{
Multi-Physics Simulation of Friction stir welding process
}

\author{
Hongjun Li, Donald Mackenzie and Robert Hamilton \\ Department of Mechanical Engineering \\ University of Strathclyde \\ James Weir Building \\ 75 Montrose Street \\ Glasgow, UK, G1 1XJ
}

\begin{abstract}
Purpose: The Friction Stir Welding (FSW) process comprises of several highly coupled (and non-linear) physical phenomena: large plastic deformation, material flow transportation, mechanical stirring of the tool, tool-workpiece surface interaction, dynamic structural evolution, heat generation from friction and plastic deformation, etc. In this paper, an advanced Finite Element (FE) model encapsulating this complex behavior is presented and various aspects associated with the FE model such as contact modeling, material model and meshing techniques are discussed in detail.
\end{abstract}

Methodology: The numerical model is continuum solid mechanics-based, fully thermomechanically coupled and has successfully simulated the friction stir welding process including plunging, dwelling and welding stages.

Findings: The development of several field variables are quantified by the model: temperature, stress, strain, etc. Material movement is visualized by defining tracer particles at the locations of interest. The numerically computed material flow patterns are in very good agreement with the general findings from experiments.

Value: The model is, to the best of the authors' knowledge, the most advanced simulation of FSW published in the literature.

Keywords: Friction Stir Welding (FSW); Multi-physics; Numerical simulation

\footnotetext{
* Corresponding author, Tel.: +44 (0) 141548 2046; Fax: +44 (0) 141552 5105; Email: r.hamilton@ @strath.ac.uk
} 


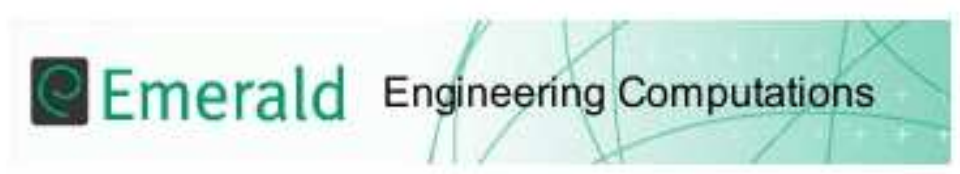

\section{Multi-Physics Simulation of Friction stir welding process}

\begin{tabular}{|r|l|}
\hline Journal: & Engineering Computations \\
\hline Manuscript ID: & EC-Apr-2009-0027.R1 \\
\hline Manuscript Type: & Research Article \\
\hline Keywords: & Friction Stir Welding (FSW), Multi-physics, Numerical simulation \\
\hline & \\
\hline
\end{tabular}

\section{scholaroNE" \\ Manuscript Central}




\section{Introduction}

Friction stir welding (FSW) provides a new technique for metal joining and processing, in which a rotating tool, with a particularly designed shape, is first inserted into the adjoining seams of the components to be welded and then travels all along the welding line. Since its inception FSW has attracted worldwide interest. The FSW process comprises of several highly coupled (and non-linear) physical phenomena: large plastic deformation, material flow transportation, mechanical stirring of the tool, tool-workpiece surface interaction, dynamic structural evolution, heat generation from friction and plastic deformation, etc. Briefly, thermal and mechanical behaviours are mutually dependent and coupled together. Full multi-physics analysis is therefore required to incorporate all the physics phenomena so as to simulate the process as close to the real FSW process as possible.

The FSW process has been investigated numerically by several researchers. Ulysse [1] presented a three dimensional visco-plastic model, using the commercial software FIDAP [2]. The heat generation was determined as the product of the effective stress and effective strain-rate. In the model, the tool rotates and the plates are fed toward the tool. A constant tangential velocity on the tool surface is specified to simulate the rotation of the tool, assuming some velocity slip at the contact surface. The transverse movement of the workpiece was modeled by prescribing a velocity boundary condition on the incoming side of the workpiece. As only the heat from deformation energy dissipation was accounted for, a thermal contact conductance can be applied at the interface to study the heat transfer between the tool and workpiece. It was concluded that the measured temperatures were consistently over predicted by the model and the discrepancies 
probably resulted from an inadequate representation of the constitutive behaviour of the material used in FSW.

Santiago et al [3] presented a similar model to [1] with the same rigid and visco-plastic material model and the same modelling technique, in which the plates move towards the rotating tool and the material flow at the interface is specified as a boundary condition. This model was meshed with tetrahedral elements of the Taylor-Hood type, with quadratic interpolations for velocities and linear interpolations for stresses. Because a static analysis method was used for both models in [1] and [3], the results estimated from the models correspond to the steady state of the FSW process. Schmidt and Hattel [4] put forward a fully coupled thermo-mechanical dynamic analysis model also aiming to achieve the steady welding state using the arbitrary Lagrangian-Eulerian formulation in ABAQUS/Explicit [5]. The solid elastic-plastic JohnsonCook material model was used:

$$
\sigma_{y}=\left[A+B\left(\bar{\varepsilon}^{p l}\right)^{n}\left(1+C \ln \frac{\dot{\bar{\varepsilon}}^{p l}}{\dot{\varepsilon}_{0}}\right)\left[1-\left(\frac{T-T_{r e f}}{T_{\text {melt }}-T_{r e f}}\right)^{m}\right]\right.
$$

where $A, B, C, m, n, T_{m e l t}$ and $T_{r e f}$ are material constants, $\bar{\varepsilon}^{p l}$ the effective plastic strain, $\dot{\bar{\varepsilon}}^{p l}$ the effective plastic strain rate and $\dot{\varepsilon}_{0}$ the normalizing strain rate. A disc-shaped plate was created for convenience of meshing. Similar to models in [1] and [3], a velocity equal to the welding speed was assigned to the materials on the incoming side of the plate. At the tool-workpiece interface, Coulomb's Law of friction was used to model the contact behavior with a constant friction coefficient of 0.3 . The greatest improvement over the previous models was the ability to predict the suitable thermo-mechanical conditions under which the weld can form. 
Lasley [5] developed a fully coupled thermo-mechanical finite element model with the transient explicit analysis capability to predict temperature evolution and material flow during the plunge phase. The commercial software Forge3 [6] was used in the analysis, specializing in modeling of high deformation forming processes which was handled by an automatic Lagrangian remeshing scheme. The temperature and strain rate dependent viscoplastic Norton-Hoff model with the Hansel and Spittel flow criteria was used in the model.

The most recent FSW model was proposed by Buffa et al [7] using DEFORM-3D ${ }^{\mathrm{TM}}$ [8], a Lagrangian implicit code. The FSW process was modelled from the initial plunge state to steady state travel. A non-uniform mesh with adaptive remeshing was adopted. A rigid-viscoplastic material model was employed and material constants were determined by numerical regression based on experimental data. It was assumed that the heat generation was due only to plastic and frictional conditions at the tool-workpiece interface. The model was able to predict the temperature, strain, strain rate as well as material flow and forces. Good agreement was obtained when comparing the results of the simulation with experimental data.

For all the coupled models listed above, only those of Lasley [9] and Buffa et al [7] attempted to simulate the full FSW process. Furthermore, the model in Lasley [9] can only simulate the plunge stage. Their models gave good prediction of strain rate and material flow; however, the deformation history information could not be obtained because a fluid-like viscoplastic material model was used. The same problems occur in other Computational Fluid Dynamic (CFD) models [10-18]. Schmidt and Hattel [4] used a material model with an elastic contribution but only steady state was simulated. The objective of present paper is to extend FSW numerical FE simulation to fully thermo-mechanically model the process using material models that can return both temperature and (residual) stress results. 


\section{Numerical Model \\ 2.1 Simulation method}

The choice of finite element method appropriate to fully coupled simulation of the FSW process is determined by a number of factors, including available models of physical phenomena, meshing capabilities, solver technology and computing requirements.

The materials in contact with the rotating tool experience very large plastic deformations and strains, and may move at a velocity close to that of the tool. In continuum solid mechanics finite element analysis, there are two commonly used methods to tackle large strain/deformation problems: Arbitrary Lagrangian-Eulerian (ALE) and complete remeshing formulations. ALE combines the advantages of both Lagrangian and Eulerian methods and allows the mesh to move independently of the material, making it possible to maintain a high-quality mesh during an analysis. The mesh topology does not change in the model, which means that the number of elements and their connectivity remains the same. In the FSW process, the tool travels a long distance along the plate, the ALE approach may fail when mesh distortion reaches unacceptable levels. To improve the simulation it would be necessary to use an FE technique which allowed remeshing of the domain, however, the computational cost of such an approach is greater than ALE and not all the FE codes incorporate a remeshing feature, (especially when using explicit solvers).

Friction stir welding is a high-speed dynamic process that can be extremely costly to analyze using implicit solvers. However, explicit solvers are well-suited for analyzing transient dynamic response and in addition allow better representation of complex contact interactions when the contact surface is not known a priori. The process itself is a coupled thermomechanical process; hence an element with both temperature and displacement degrees of 
freedom should be used. If the material is assumed to be viscoplatic, elements with mixed formulation in terms of velocity and pressure fields are preferred. However, a viscoplastic model cannot return residual stress as a result of the analysis. A temperature and strain rate dependent material model incorporating the effect of elastic deformation is required to fully determine for the flow, temperature, stress (residual) and strain of the workpiece material near the tool.

Taking the above factors into account, it was decided to base the simulation on ABAQUS/EXPLICIT [5] analysis using the ALE formulation and a temperature and rate dependent isotropic hardening plasticity material model to perform a fully coupled explicit solution of the FSW process.

\subsection{Governing equations and numerical formulations}

\subsubsection{Heater transfer equations}

The heat transfer equation for the workpiece can be written as

$$
\nabla \cdot\left([k \nabla T)+Q=\rho c \frac{\partial T}{\partial t}\right.
$$

where $k$, is the property of thermal conductivity, $Q$ is the heat source, $\nabla$ represents the $\operatorname{grad}$ operator and $\nabla$.the divergence operator. In ABAQUS/Explicit the explicit forward-difference time integration rule is used as illustrated in Schmidt and Hattel [4].

The heat generated by plastic strain energy dissipation is calculated by:

$$
r^{p l}=\eta_{f} \mathbf{S} \dot{\boldsymbol{\varepsilon}}^{p l}
$$

where $\eta_{f}$ is a user-defined factor, $\mathbf{S}$ is the deviatoric stress, and $\dot{\boldsymbol{\varepsilon}}^{p l}$ is the rate of plastic straining. The rate of frictional energy dissipation is given by:

$$
p_{f r}=\tau \cdot \dot{\gamma}
$$

where $\tau$ is the frictional stress and $\dot{\gamma}$ is the slip rate.

In the model, only the convective heat transfer boundary condition was applied:

$$
k \frac{\partial T}{\partial n}+h_{f}\left(T-T_{S}\right)=0
$$


where $h_{f}$ is the film coefficient and $T_{S}$ the surrounding medium temperature.

\subsubsection{Mechanical equations}

The governing equation for the mechanical response of the process is the equilibrium equation:

$$
\rho \mathbf{a}=\rho \mathbf{g}+\operatorname{div}(\boldsymbol{\sigma})
$$

where $\boldsymbol{\sigma}$ is the stress tensor, $\mathbf{g}$ the body force per unit mass and a the acceleration.

In ABAQUS/Explicit the central difference rule is used as illustrated in Schmidt and Hattel [4].

\subsubsection{Constitutive equations}

The material model for the workpiece is chosen as temperature and rate dependent isotropic hardening plasticity. The Johnson-Cook material law as expressed in Equation (1) was selected. Hooke's law is used to express the elasticity relationship,

$$
\boldsymbol{\sigma}=\lambda \operatorname{trace}\left(\boldsymbol{\varepsilon}^{e l}\right) \mathbf{I}+2 \mu \boldsymbol{\varepsilon}^{e l}
$$

where $\operatorname{trace}\left(\boldsymbol{\varepsilon}^{e l}\right)=\boldsymbol{\varepsilon}_{i i}^{e l}=\sum_{i=1}^{n} \boldsymbol{\varepsilon}_{i i}^{e l}, \lambda$ and $\mu$ are elastic constants. Elastoplastic behaviour is described by decomposing the strain rate or strain increment into elastic and plastic parts.

$$
\dot{\varepsilon}=\dot{\varepsilon}^{e l}+\dot{\varepsilon}^{p l}
$$

Jaumann stress rate is employed to define the material behaviour, that is, the stress rate is purely due to the elastic part of the strain rate and shown in terms of Hook's law by

$$
\dot{\boldsymbol{\sigma}}=\lambda \operatorname{trace}\left(\dot{\boldsymbol{\varepsilon}}^{e l}\right) \mathbf{I}+2 \mu \dot{\boldsymbol{\varepsilon}}^{e l}
$$

or, in component fomat,

$$
\dot{\sigma}_{i j}=\lambda \delta_{i j} \dot{\varepsilon}_{k k}^{e l}+2 \mu \dot{\varepsilon}_{i j}^{e l}
$$

the Jaumann rate equation is integrated in a corotational framework,

$$
\Delta \boldsymbol{\sigma}=\lambda \operatorname{trace}\left(\Delta \boldsymbol{\varepsilon}^{e l}\right) \mathbf{I}+2 \mu \Delta \boldsymbol{\varepsilon}^{e l}
$$

The Mises yield function is assumed,

$$
\sqrt{\frac{3}{2} \mathbf{S}: \mathbf{S}}-\sigma_{y}=0
$$


where $\mathbf{S}: \mathbf{S}=S_{i j} S_{i j}, \sigma_{y}$ is uniaxial yield stress, is defined as a function of equivalent plastic strain, strain rate and temperature. $S$ is the deviatoric stress and $p$ the hydrostatic pressure.

$$
\begin{aligned}
& \mathbf{S}=\boldsymbol{\sigma}+p \mathbf{I} \\
& p=-\frac{1}{3} \operatorname{trace}(\boldsymbol{\sigma})
\end{aligned}
$$

Equivalent plastic strain is given by,

$$
\begin{aligned}
& \bar{\varepsilon}^{p l}=\int_{0}^{t} \dot{\bar{\varepsilon}}^{p l} d t \\
& \dot{\bar{\varepsilon}}^{p l}=\sqrt{\frac{2}{3} \dot{\boldsymbol{\varepsilon}}^{p l}: \dot{\boldsymbol{\varepsilon}}^{p l}}
\end{aligned}
$$

And the plastic flow law is:

$$
\dot{\boldsymbol{\varepsilon}}^{p l}=\frac{3}{2} \frac{\mathbf{S}}{\sigma_{y}} \dot{\bar{\varepsilon}}^{p l}
$$

\subsection{Model description}

The FSW configuration modelled is shown in Figure 1. A single, complete plate was used rather than two butted panels to give a continuum model. The workpiece is $60 \mathrm{~mm}$ long, $30 \mathrm{~mm}$ wide and $3 \mathrm{~mm}$ thick. The tool has a conical shoulder surface to accommodate material pushed out when the tool probe is inserted into the plate. Three stages of the friction stir welding process are modelled: plunge, dwell and traverse, as shown in Figure 2.

The thermo-mechanical material properties of aluminium alloy AA2024-T3, as reported in [19], were used in the model and are given in table 1. An 8-node three dimensional temperature-displacement coupled element, C3D8RT, with reduced integration and hourglass control was used to model the workpiece.

Table 1 Material constants for the Johnson-Cook strain rate dependent yield stress [19 ].

\begin{tabular}{|l|l|l|l|l|l|l|}
\hline $\mathrm{A}(\mathrm{MPa})$ & $\mathrm{B}(\mathrm{MPa})$ & $\mathrm{n}$ & $\mathrm{C}$ & $\mathrm{m}$ & $\mathrm{T}_{\text {melt }}\left({ }^{\circ} \mathrm{C}\right)$ & $\mathrm{T}_{\text {ref }}\left({ }^{\circ} \mathrm{C}\right)$ \\
\hline 369 & 684 & 0.73 & 0.0083 & 1.7 & 502 & 25 \\
\hline
\end{tabular}


It was found that solution times for the model were very long and it was necessary to carry out a mesh study [20] to choose a computationally economic mesh design for the model while maintaining the quality of the mesh during deformation. A smaller plate was used instead of the whole model to explore the effect of mesh size. Additionally only the plunge and dwell stages were simulated in the mesh study. The number of elements through thickness and in horizontal plane were varied. The typical solution time in the mesh study, for a single run, was 1 to 3 days depending on the size of mesh used. For brevity a full description is not included here. Based on the mesh study, the element size in the horizontal plane was chosen as $0.5 \mathrm{~mm} \times 0.5 \mathrm{~mm}$ and $1 \mathrm{~mm}$ in thickness direction. The tool and backing plate were modelled as rigid isothermal surfaces, as shown in figure 3. The total solution time for a full simulation of the FSW process, including plunge, dwell and traverse stages, running on a PC with a 2.0 Ghz AMD Opteron Dual Core processor, was 21 days and 6 hours .

The whole plate was defined as an adaptive domain, where the material can move independently of the FE mesh. In the adaptive mesh domain, the top surface in contact with the tool was defined as a sliding surface region, where the mesh follows the material movement in the normal direction to the surface and moves independently of the underlying material in the tangential direction.

Contacts between the tool and workpiece and between workpiece and backing plate were simulated using the contact pair algorithm, as it is the only algorithm that can be used for coupled thermo-stress analysis in ABAQUS/EPLICIT. At the tool-workpiece interface, Coulomb's law of friction is applied with a constant friction coefficient. At the backing plate-workpiece plate, frictionless condition is assumed. The backing plate is fully fixed and the edges of bottom surface of the workpiece are constrained so that no rigid body movement is allowed. A constant temperature field equal to the environmental temperature is prescribed for the whole model at the beginning of the analysis. All the surfaces of the workpiece were assumed to have convection boundary conditions. The bottom surface in contact with backing plate has a convection coefficient of $1000 \mathrm{~W} / \mathrm{m}^{2} \mathrm{~K}$, while the rest surfaces of the plate have a much lower convection coefficient, $10 \mathrm{~W} / \mathrm{m}^{2} \mathrm{~K}[4]$. 
The tool had a penetration speed of $0.25 \mathrm{~mm} / \mathrm{s}$ and a plunging time of 8.3 seconds which equates to a sinking depth of $0.075 \mathrm{~mm}$. Following the plunge stage was the 0.1 second dwell phase. This was found to be appropriate to generate a suitable temperature field and to keep the welding material in a well-plasticized state so that a sound weld can be produced [7]. The welding speed and welding time during the final traverse stage were set to $2 \mathrm{~mm} / \mathrm{s}$ and 14 seconds, respectively.

To avoid sudden initial transverse movement of the tool (i.e. infinite acceleration at the onset of welding) the traverse travelling speed was defined by a series of values at points in time in ABAQUS, as shown in Figure 4.

\section{Results}

\subsection{Temperature}

The model can predict temperature evolution through the whole process and over the whole volume. Figure 5 shows the temperature distributions in degrees centigrade $\left({ }^{\circ} \mathrm{C}\right)$ at six representative time points $6.8 \mathrm{~s}, 8.3 \mathrm{~s}, 8.4 \mathrm{~s}, 10.4 \mathrm{~s}, 15.4 \mathrm{~s}$ and $22.4 \mathrm{~s}$. (Note plunge occurs from 0 to $8.34 \mathrm{~s}$, dwell occurs $8.3 \mathrm{~s}$ to $8.4 \mathrm{~s}$ and traverse occurs $8.4 \mathrm{~s}$ to $22.4 \mathrm{~s}$ ) The top row pictures give the cross-section views along the welding joint line while the bottom row pictures provide the views from the top.

When only the pin was in contact with the workpiece, the maximum temperature in the workpiece occurred somewhere adjacent to the edge of the pin bottom surface. At $6.8 \mathrm{~s}$ the shoulder surface started to contact the workpiece, thereafter, the maximum temperature moved towards the corner between pin and shoulder surfaces. At $8.3 \mathrm{~s}$ the full contact condition was established between tool surface and top surface of the workpiece, where upon the maximum temperature was around the shoulder-workpiece interface. A high temperature gradient with a "basin" or "V" shape appeared in the workpiece beneath the tool demonstrating high heat flux between the interface layer and workpiece's material outside the shoulder radius. After the $0.1 \mathrm{~s}$ dwelling, at $8.4 \mathrm{~s}$, the temperature was distributed more even between the leading side and trailing side of the tool. Then the tool started to traverse to join the plates together. The welding process quickly reached steady state and the temperature distribution pattern around the tool exhibited little variation as displayed at $10.4 \mathrm{~s}, 15.4 \mathrm{~s}$ and $22.4 \mathrm{~s}$ in Figure 5. 
The temperature contour looks almost symmetric along the joint line on both the retreating and advancing sides. This means the rotating motion of the tool will not significantly affect the temperature distribution in the work piece.

The maximum temperature was found to be greater than melting point, which for this material was $502^{\circ} \mathrm{C}$. The reason for this is possibly due to the nature of the assumed interaction between the tool and workpiece. The tool was assumed to be rigid isothermal and had no temperature DOF, there was no direct heat transfer between the tool and workpiece. Only a concentrated heat capacity was specified and $20 \%$ of the total frictional energy was set to flow into the tool. The remaining $80 \%$ of the frictional energy together with the plastic dissipation energy could possibly account for the temperature in an element being greater than the melting point. In reality, the fraction of frictional energy into the workpiece depends on the temperature and heat conductivities in the tool and workpiece. The total frictional energy was calculated with a constant friction coefficient, which is a function temperature and contact pressure. However the most plausible reason is thought to do with mass scaling. During the simulation process, elements near the tool typically experience large amounts of deformation (especially the plunge stage). The reduced characteristic element length causes a smaller global time increment and therefore increased solution time. Scaling the mass of these elements throughout the analysis can significantly decrease the computation cost, a fixed mass factor, 10000 was chosen for the coupled FSW model [20]. This significantly increased material density had changed the original physical problem as the density is involved in both the mechanical and thermal governing equations. However given that the final solution time for the model was 21 days and 6 hours, mass scaling was deemed as a necessity to allow solution in a reasonable time frame.

\subsection{Stress distribution}

One of the most important features of the proposed model is the ability to predict the stress distributions (active stress and residual stress) over the whole FSW process. Figure 6 shows the von Mises stress plots $\left(\mathrm{N} / \mathrm{m}^{2}\right)$ at nine characteristic time points, $0.4 \mathrm{~s}, 1.0 \mathrm{~s}, 3.0 \mathrm{~s}, 6.6 \mathrm{~s}, 7.1 \mathrm{~s}, 8.3 \mathrm{~s}$, $10.4 \mathrm{~s}, 15.4 \mathrm{~s}$ and $22.4 \mathrm{~s}$ from the start of the process. At the commencement of plunging, an axial force was exerted on the material beneath the tool pin causing an area of high compressive stress in the workpiece. With the growth of the heat at the pin-workpiece interface, the material progressively softens. At 3.0s the stress in the plates under the tool pin nearly approached zero 
caused by the extremely high temperature in this area, signified from the constitutive equations. By 3.0 seconds the maximum stress migrated to somewhere remote from the pin-workpiece interface. However at 6.6 seconds there was still a cylindrical layer of material surrounding the tool pin that had fairly high stress as shown in the von Mises stress plot.

After the tool shoulder touched the workpiece at $6.8 \mathrm{~s}$, the cylindrical high stress layer gradually disappeared since the material was heated up by the heat generated at the shoulder-pin interface. At $8.3 \mathrm{~s}$ most of the material under the tool was softened and in a state that it could be easily stirred. During the welding stage, from $8.4 \mathrm{~s}$ onwards, no obvious variation in the stress field around the tool was found. This is due to the fact that the temperature distribution around the tool after $8.4 \mathrm{~s}$ reached a steady state as shown in Figure 5. From the observation of the stress evolution throughout the process, it can be seen that the temperature imposes a significant effect on the stress and consequently on the formation of the weld.

The last picture in Figure 6 shows the von Mises stress distribution at 22.4s. The maximum von Mises stress in the region close to the starting position of the welding, increased from zero up to $270 \times 10^{6} \mathrm{~N} / \mathrm{m}^{2}$. However the stress in the region nearer to the tool was quite low. This could be the result of the small model used which is only $60 \mathrm{~mm}$ long and $30 \mathrm{~mm}$ wide. The temperature was still very high over the whole plate at $22.4 \mathrm{~s}$ as shown in the last picture of Figure 5 . If the workpiece cooled down it is expected that a distinctive residual stress could be identified along the weld.

\subsection{Plastic strain}

The weld microstructure strongly depends on the thermal cycle and plastic deformation that the material experienced. The ability of the model to calculate the plastic strain and strain rate makes the prediction of the microstructure possible. In the present study only the plastic strain profile is discussed. As an example, Figure 7 illustrates the equivalent plastic strain contour at 13.4s from three perspectives, namely, top view, longitudinal cross section view (BB) and transverse crosssection view (CC). It is apparent that the plastic strain distribution is not symmetric about the joining line and the advancing side has a higher average plastic strain than the retreating side. This is consistent with the findings in [7] and [21]. The highest plastic region is still along the welding line with a width close to the pin diameter. 


\subsection{Tool reaction force and moment}

Predicting the tool reaction force and moment is another distinctive feature of the current model. Most of the 3D FE models in the literature can only compute the force in the welding stage when the steady state has been established. However it is well known that the pin is subject to the highest reaction forces in the plunge stage, as revealed in the experimental work [22]. The considerable stresses that the pin experienced can lead to failure if the mechanical strength is not sufficient. To prevent tool damage and improve its fatigue life, it is necessary to know, reasonably accurately, the tool reaction forces and torque over the whole process.

The variation of the tool axial $(Z)$ reaction forces, RFZ, for the whole process is illustrated in Figure 8 . The plunge stage, at a constant speed, occurs during the first 8.3 seconds. The value of the reaction forces in the transverse $(\mathrm{X})$ and longitudinal $(\mathrm{Y})$ directions are very small compared with the axial $(Z)$ reaction force and hence are not shown for brevity. The "RFZ" curve climbs quickly for the first two seconds and then falls significantly to a low value at $5 \mathrm{~s}$. During the next half second the curve suddenly increases again before reaching, at around 7s, a value just below the previous maximum. This is followed by a period of gradual decrease with fluctuation. The deep drop to a minimum at about $5 \mathrm{~s}$ is thought due to the abrupt local material temperature increment under the tool pin. As previously mentioned, the predicted temperature in the analysis, was above the melting temperature for the material. Due to the overestimated temperature the predicted force history in plunge stage probably requires further verification.

Figure 9 illustrates the variation of the tool reaction moments with time. "RMX" and "RMZ" stand for the reaction moment components about the $\mathrm{X}$ and $\mathrm{Z}$ axis, respectively. The reaction moment about the $\mathrm{Y}$ axis is small compared with the other two and not shown for clarity. At $6.8 \mathrm{~s}$ when the tool started to contact the workpiece, the curves jumped to its peak value which is much higher than the previous maximum before $6.8 \mathrm{~s}$. After $8.4 \mathrm{~s}$ in the dwell and traverse stages the curve gradually decreases with fluctuation.

The fluctuation shown in figures 8 and 9 could suggest problems with stability in the numerical solution possibly related to mass scaling. 


\subsection{Heat generation}

Heat generated from both friction and plastic deformation is plotted against time as shown in Figures 10 and 11. Frictional energy dissipation and plastic dissipation increase in a bilinear manner. There is a smooth transition region around $6 \mathrm{~s}$ and generation rates become higher after 6.8s. In the current model results, friction was responsible for generating most of the heat needed (98\%) even when full contact condition had established and severe plastic deformation occurred, indicating the sliding condition is dominant at the contact interface.

The model used a constant friction coefficient, 0.3 [4] and neglected its temperature dependence. The surface interaction involving contact pressure, friction, temperature dependence etc, is very complicated and at present is not fully understood. During the process, the friction force may also cause the maximum yield shear stress in the workpiece material to be exceeded. The current assumed contact condition is therefore far from the real situation. However due to the uncertainty in the literature as to the nature of the surface interaction, it was decided, in this study as a first step, to keep the contact model definition relatively simple. It is anticipated that a more complex friction model, or one that at least considers the temperature effect, should give more accurate results and the percentage of generated heat due to frictional effects will be expected to reduce.

\subsection{Material movement}

The material flow during FSW is complicated and directly influences the properties of a FSW weld. It is of vital importance to understand the deformation process and basic physics of the material flow for optimal tool design. To visualize the material flow phenomenon, tracer particle sets were defined symmetrically, each side, along the welding line to track the material movement at specific locations. Seven tracer particle sets numbered 1 to 7 , were used and highlighted by the red points in Figure 12. Each tracer set includes a few particles in a line or/and in a plane and their initial positions are clearly shown in the figure.

The displacement for several representative particles in tracer set "tracer1" is plotted in Figures 13 and 14. This tracer particle set was only defined in the first 15 seconds to reduce the size of the results file. The selected particles are numbered in the Figure 15. The downward movement of the tool was displacement controlled at a constant speed. This was reflected by the plot of the 
displacement magnitude of tracer particle 30 which is directly under the centre of the tool, having a linear straight line. Particle 28 at the edge of the pin was pushed aside when then pin started plunging hence it had small displacement until stirred by the shoulder. Particle 29 which is also below the pin bottom surface but with a distance of half a tool pin radius from the pin centre experienced largest displacement (among all the tracer particles defined in current model) until about 7.5 seconds, indicating this area of the material suffered most of the stir at the beginning of the plunge. A quasi-linear increment was identified for particles remote from the intense stirring zone. This could be explained as the result of global workpiece deformation. The workpiece was fixed by constraining its bottom edge nodes, so when the tool pin was inserted into the workpiece the material under the tool pin was pushed downwards and the workpiece outside the pin radius bulged upwards. Particle 25, which was initially under the edge of tool shoulder, moved outside the shoulder radius during tool penetration. From then on, it had no contact with the tool, thus its displacement over the whole process was very small and purely due to the global workpiece deformation, as illustrated by the red curve in Figures 13 and 14. There was no contact with the tool either for particles 28, 36 and 42 before $7.8 \mathrm{~s}$, but once touched and stirred by the tool, the displacement suddenly increased. A key time point can be identified at about $8.4 \mathrm{~s}$, after which all the particles in contact with the tool experienced significant boost in displacement within a very short period. At this moment, it could be said say that the material is in a flow state and ready for welding.

Figure 16 and Figure 17 demonstrate the particle locations of set tracer 4 and set tracer $2 \& 3$ at several representative time points, respectively. The particle set tracer4 is a line of material points in front of the tool perpendicular to the joining line (see Figure 16). While set tracer2 and set tracer3 sit in separate lines along the welding direction, lying on the retreating side and advancing side of the weld, respectively.

For set tracer4 the material points close to the centre line was first touched and sucked into the conical shoulder-workpiece interface as shown in the pictures (top and cross-section views) of Figure 16 at 8.8s (second from the left in top row and second from the right in bottom row). Then the material points from advancing side were forced and squeezed to the retreating side, leading to a non-symmetrical flow field. Most of the particles entering onto the retreating side under the tool shoulder went through several revolutions and dropped off in the wake of the shoulder later on, mainly on the advancing side. There were also some particles, primarily from retreating side, 
at the contact interface that didn't rotate with the shoulder. They remained on retreating side when left behind by the tool. Finally the material particles formed an arc-shaped strip behind the tool. This banded shape is already well known by numerous experimental studies in the literature [23].

For set tracer2 in Figure 17 the particles entered shoulder-workpiece interface and rotated with the shoulder only for a very short time. They were directly pushed back to the wake with the advancing of the tool towards the welding direction. It is noted that the material particles never flowed with the tool into the rotational zone. Again in Figure 17, tracer3 particles were stirred into the rotational zone at various places and then sloughed off from the welding tool. Those findings are consistent with observations in experiments [23-26]. Thus the ability of the model to predict the material movement is well validated.

However, it should be noted that only a limited number of tracer particles were defined and the flow on the top surface of the workpiece is dominated by the shoulder rather than by the pin. The material has a quite different flow pattern at mid section and the lower part of the pin. To fully track and study the material flow more tracer particles should be defined and seeded.

\section{Conclusion}

The multiphysics model proposed in this paper has successfully simulated the plunge, dwell and traverse stages of the friction stir welding process. The development of field variables: temperature, stress and plastic strain, are quantified by the model. The predicted maximum temperature is higher than material melting point, resulting in a lower stress field than expected around the tool during welding. Material movement is visualized by defining tracer particles at the locations of interest. The numerically computed material flow patterns are in very good agreement with the general findings in experiments.

In the future, the foremost model refinement work will involve lowering the predicted maximum temperature values, by changing boundary conditions, mass scaling factors, heat partition between the tool and workpiece. The fluctuations shown in some of the results could suggest problems with stability in the numerical solution possibly related to mass scaling. This will be investigated in future work. 


\begin{abstract}
Also the temperature dependent Young's modulus, friction coefficient and shear stress limit can lead to better temperature predictions.

To further study the material movement behavior at the tool-workpiece interface, more tracer particles need to be seeded and parametric studies of process parameters will be performed.
\end{abstract}

\title{
References:
}

[1] Ulysse, P. (2002), "Three-dimensional Modelling of the Friction Stir-welding Process", International Journal of Machine Tools \& Manufacture, Vol. 42, pp. 1549-1557.

[2] FIDAP (1994), Fluid Dynamic Analysis Package, version 7.6, Fluid Dynamics International, Evanston, IL.

[3] Diego, H., Santiago, Lombera, F., Urquiza, S., Cassanelli, A. (2004), "Numerical Modeling of Welded Joints by the Friction Stir Welding Process", Materials Research, Vol. 7, No. 4, pp. 569-574.

[4] Schmidt, H. and Hattel, J., (2005), "A Local Model for the Thermo-mechanical Conditions in Friction Stir Welding", Modelling and Simulation in Materials Science and Engineering, Vol. 13, pp. 77-93.

[5] ABAQUS/EXPLICIT (2006), Version 6.6-1, ABAQUS, Inc., Providence, USA.

[6] Forge 3 (2004), Release 6.3. Transvalor S.A.

[7] Buffa, G., Hua, J., Shivpuri, R., Fratini, L. (2006), “A Continuum Based Fem Model for Friction Stir Welding-Model Development", Material Science and Engineering A, Vol. 419, Issues 1-2, pp. 389-396.

[8] DEFORM-3D, Scientific Forming Technologies Corporation (SFTC), Columbus, Ohio

[9] Lasley, M.J., (2005), “A Finite Element Simulation of Temperature and Material Flow in Friction Stir Welding”, Unpublished thesis, Brigham Young University, Provo, UT.

[10] Bendzsak, G.J., North, T.H. and Smith, C.B. (2000), “An experimentally validated 3D model for friction stir welding", Proceedings of the Second International Symposium on Friction Stir Welding, TWI Ltd., Gothenburg, Sweden.

[11] Colegrove, P., (2000), "Three Dimensional Flow and Thermal Modelling of the Friction Stir Welding Process", Proceedings of the 2nd International Symposium on Friction Stir Welding, Gothenburg, Sweden. 
[12] Seidel, T.U. and Reynolds, A.P., "Two-dimensional Friction Stir welding Process Model Based on Fluid Mechanics", Science and Technology of Welding \& Joining, Vol. 8, No. 3, pp. 175-183.

[13] Askari, A., Silling, S., London, B., and Mahoney, M. (2001), Modeling and Analysis of Friction Stir Welding Processes, the Minerals, Metals and Materials Society.

[14] Colegrove, P.A. and Shercliff, H.R (2005), "3-Dimensional CFD modelling of flow round a threaded friction stir welding tool profile", Journal of Materials Processing Technology, Vol. 169, No. 2, pp. 320-327.

[15] Sellars, C.M. and Tegart, W.J. (1972), "Hot Workability", International Metallurgical Review, 17, pp. 1-24.

[16] Nandan, R., Roy, G.G. and DebRoy, T. (2006), "Numerical Simulation of ThreeDimensional Heat Transfer and Plastic Flow During Friction Stir Welding", Metallurgical \& Materials Transactions A, Vol. 37, pp. 1247-1259.

[17] Nandan, R., Roy, G.G., T. J. Lienert, and DebRoy, T. (2006), "Numerical Modelling of 3D Plastic Flow and Heat Transfer during Friction Stir Welding of Stainless Steel" Science and Technology of Welding \& Joining, Vol. 11, No. 5, pp. 526-537.

[18] Nandan, R., Roy, G.G., T. J. Lienert, and DebRoy, T. (2007), "Three-dimensional Heat and Material Flow during Friction Stir Welding of Mild steel”, Acta Materialia, Vol. 55, pp. 883-895.

[19] Lesuer, D. R. (2000), Technical Report FAA and DOE, USA

[20] Hongjun Li, (2008), "Coupled Thermo-Mechanical Modelling of Friction Stir Welding Process", PhD Thesis, Univ. of Strathclyde.

[21] Heurtier, P., Desrayaud, C., and Montheillet, F. (2002), "A Thermomechanical Analysis of the Friction Stir Welding Process", Materials Science Forum, Vol. 396, No. 4, pp. 1537-1542.

[22] Lienert T.J., Stellwag W.L. Jr., Grimmett, B.B., and Warke, R.W., (2003), "Friction Welding Studies on Mild Steel”, Supplement to the Welding Journal, Vol. 82(1), pp. 1s-9s.

[23] Seidel, T.U. and Reynolds, A.P. (2001), "Visualization of the Material Flow in AA2195 Friction-Stir Welds Using a Marker Insert Technique", Metallurgical and materials Transactions A, Vol. 32, pp. 2879.

[24] Schmidt, H.N.B., Dickerson, T.L. and Hattel, J.H. (2006), "Material flow in butt friction stir welds in AA2024-T3", Acta Materialia, Vol. 54, pp. 1199-1209.

[25] Reynolds, A.P. (2000), "Visualisation of material flow in autogenous friction stir welds", Science and Technology of Welding \& Joining, Vol. 5, No. 2, pp. 120-124. 
[26] Mishra, R.S. and Ma, Z.Y. (2005), "Friction stir welding and processing", Materials Science and Engineering: R: Reports, Vol. 50, No. 1-2, pp. 1-78.

1

2

3

4

5

6

7

8

9

10

11

12

13

14

15

16

17

18

19

20

21

22

23

24

25

26

27

28

29

30

31

32

33

34

35

36

37

38

39

40

41

42

43

44

45

46

47

48

49

50

51

52

53

54

55

56

57

58

59

60

http://mc.manuscriptcentral.com/engcom 


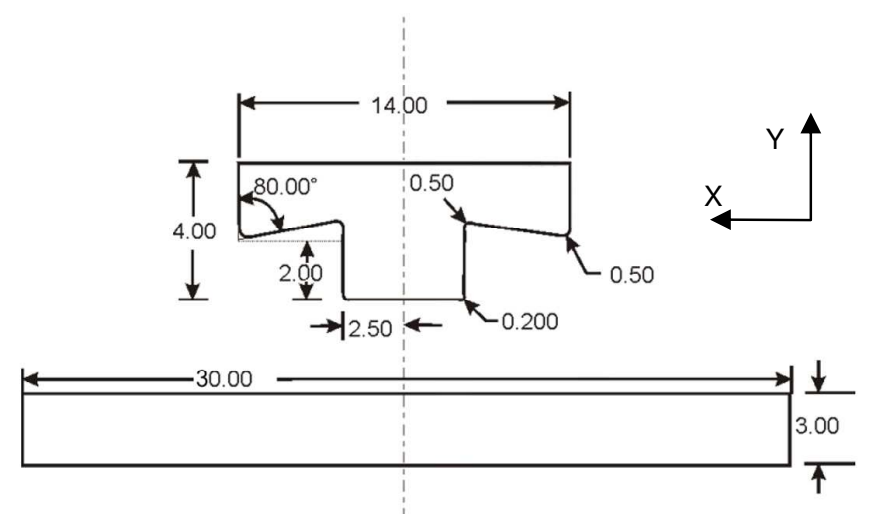

Figure 1. FSW model geometry (in $\mathrm{mm}$ ) 


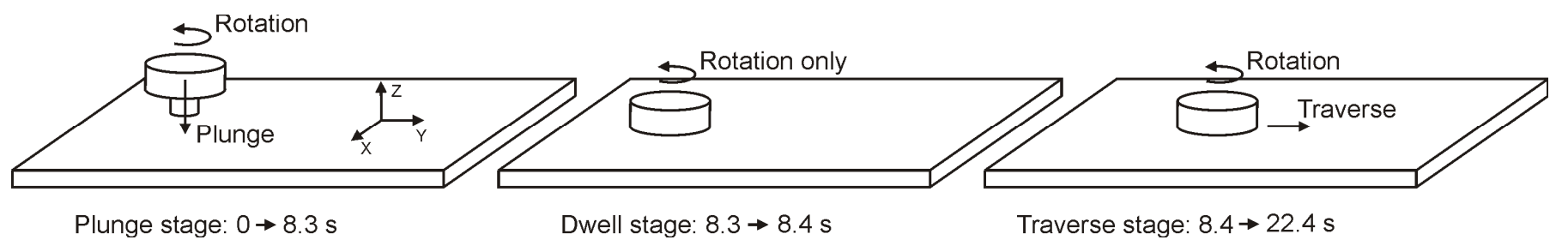

Figure 2. The three stages of FSW simulated in the FE model 


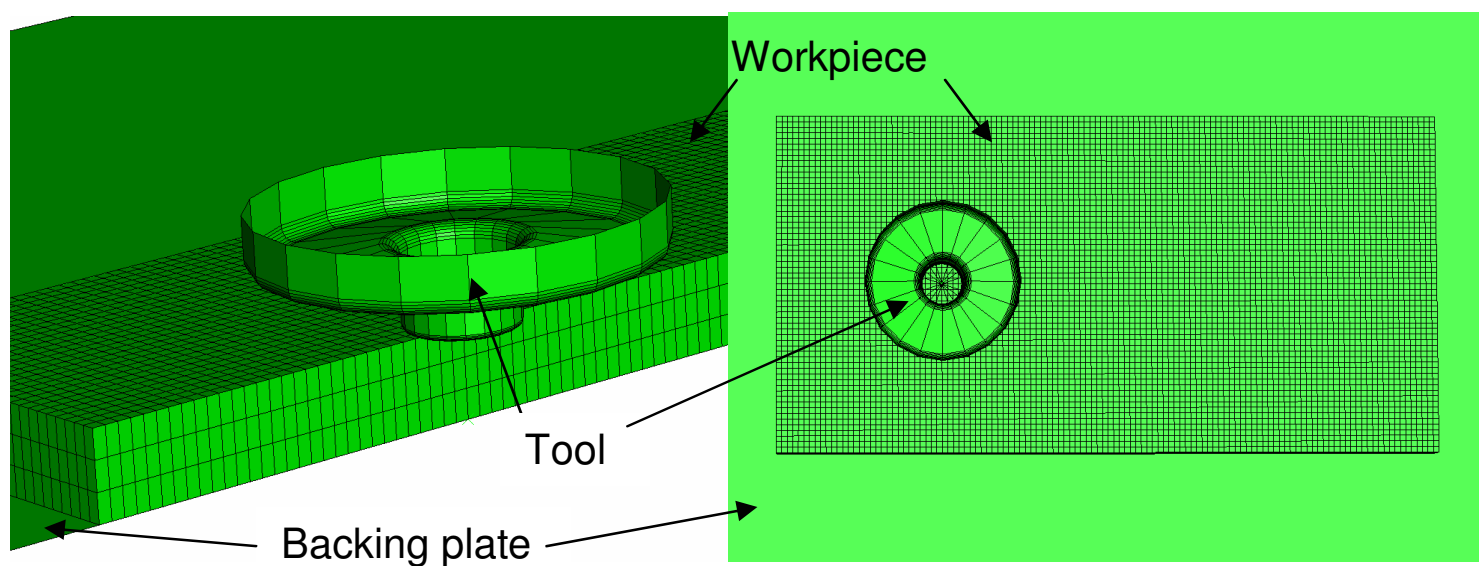

Figure 3. Finite Element model for FSW process 


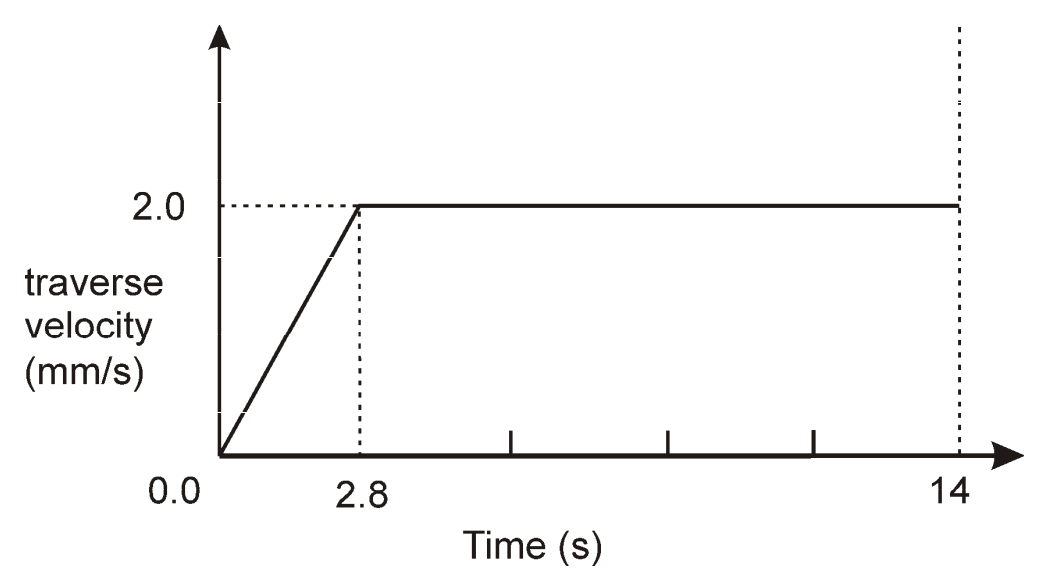

Figure 4. Traverse velocity versus time in the traverse stage. 

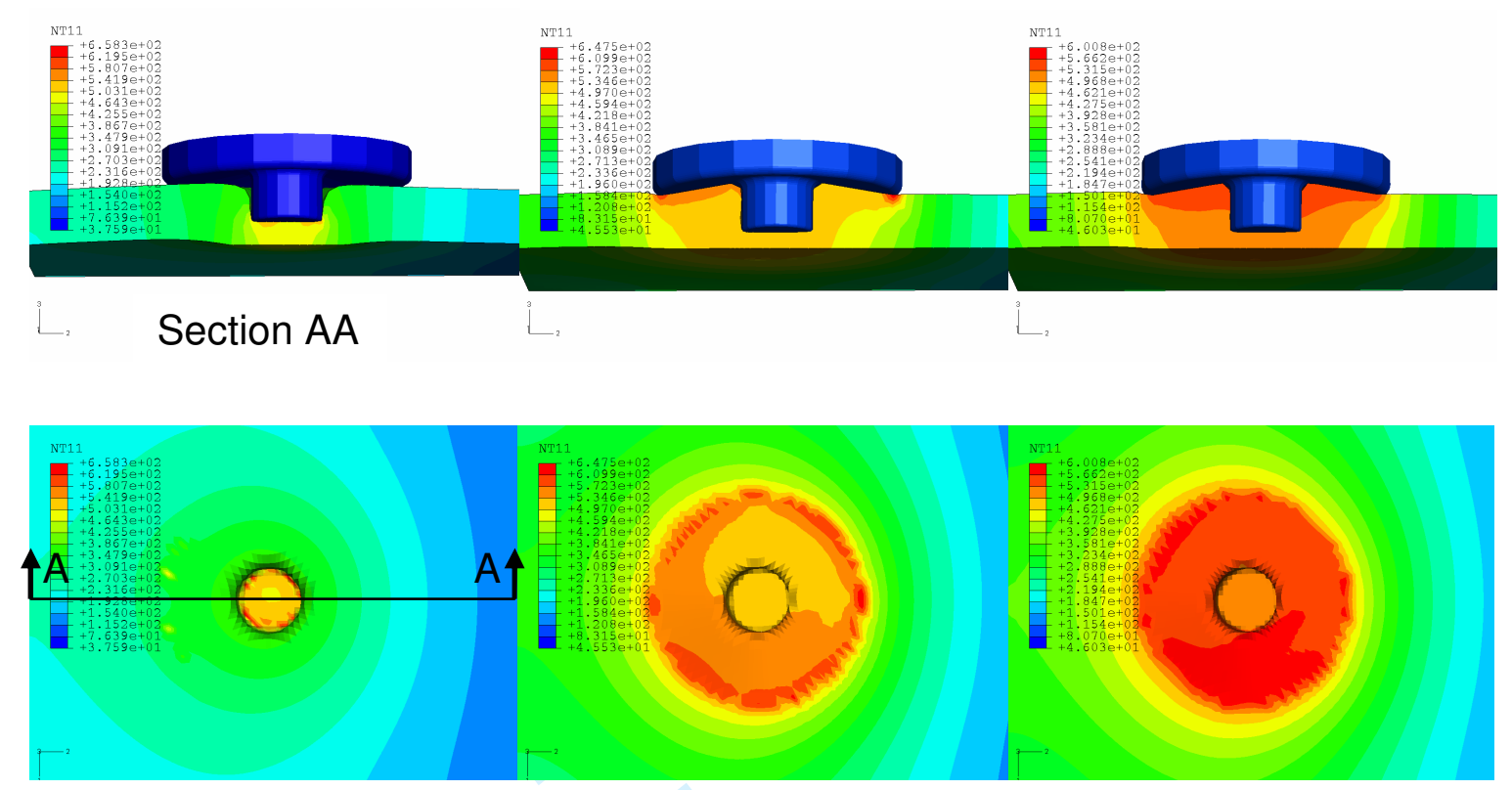
$6.8 \mathrm{~s}$
$8.3 \mathrm{~s}$
$8.4 \mathrm{~s}$

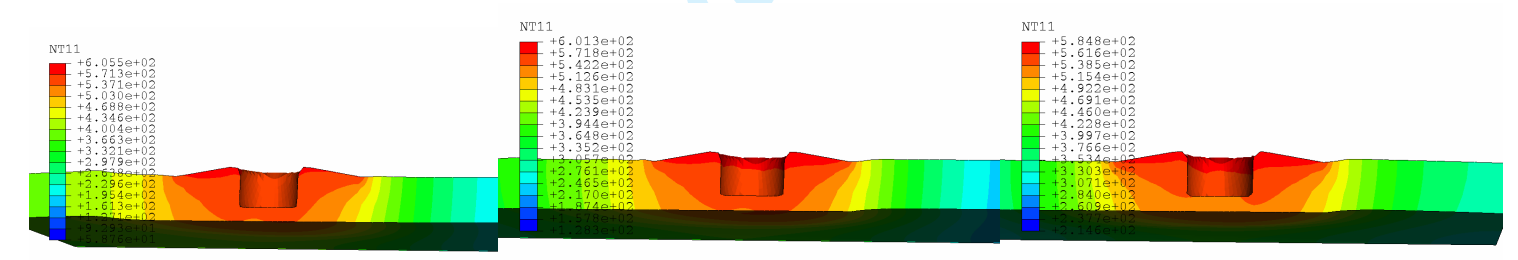

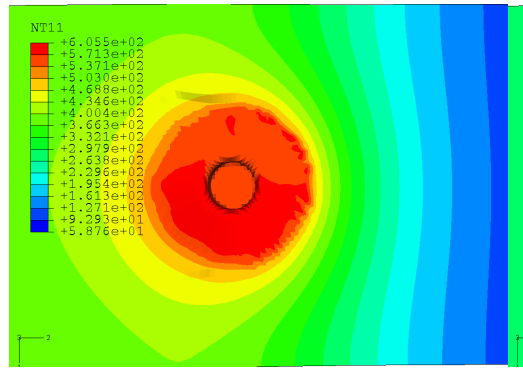

$10.4 \mathrm{~s}$

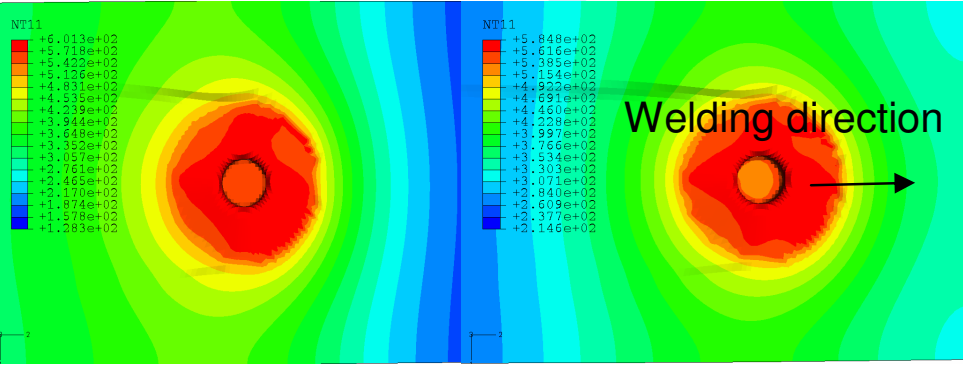

Figure 5. Temperature distributions $\left({ }^{\circ} \mathrm{C}\right)$ in the workpiece at time $\mathrm{t}=6.8,8.3,8.4,10.4,15.4$ and 22.4 seconds. 

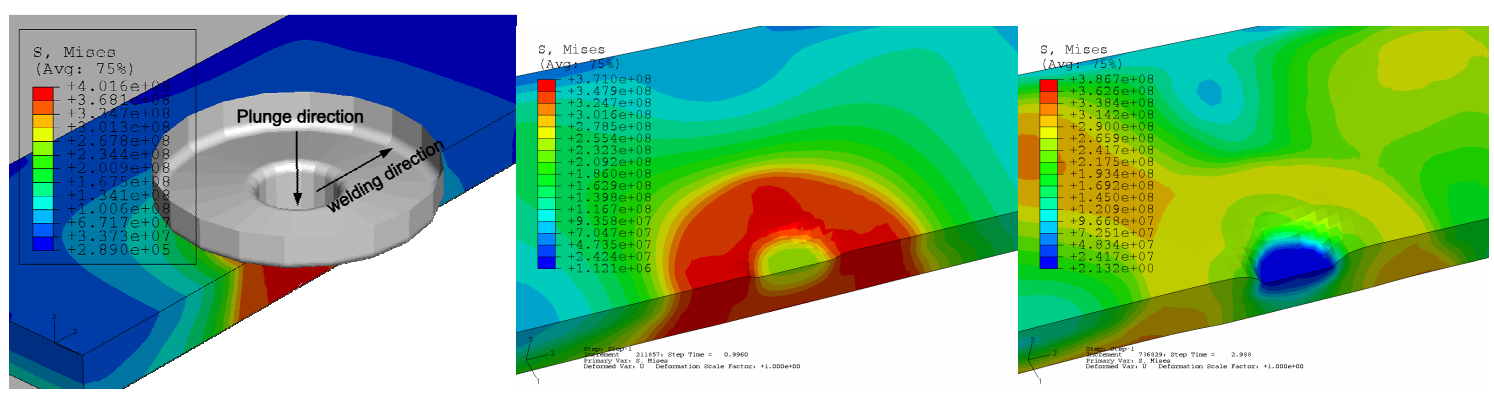
$0.4 \mathrm{~s}$
$1.0 \mathrm{~s}$
$3.0 \mathrm{~s}$
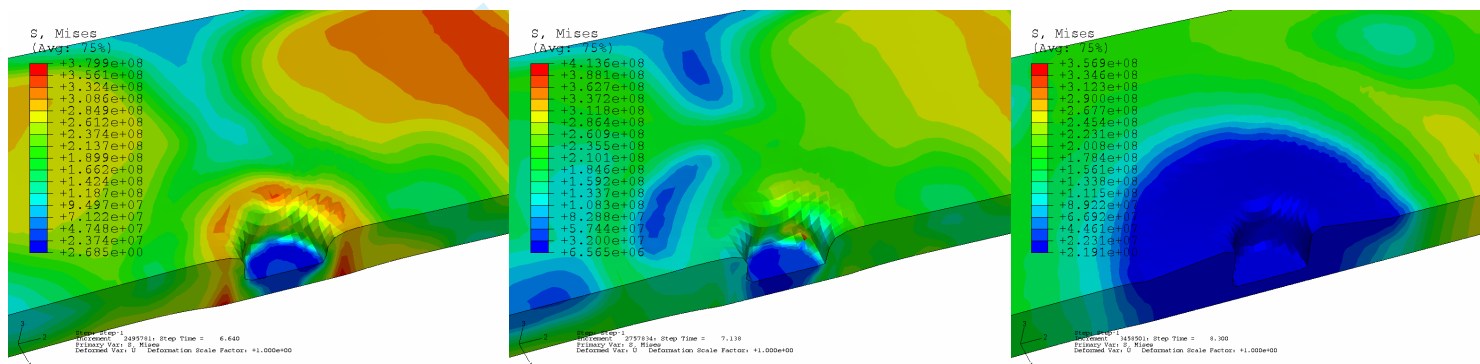

$6.6 \mathrm{~s}$

$7.1 \mathrm{~s}$

$8.3 \mathrm{~s}$
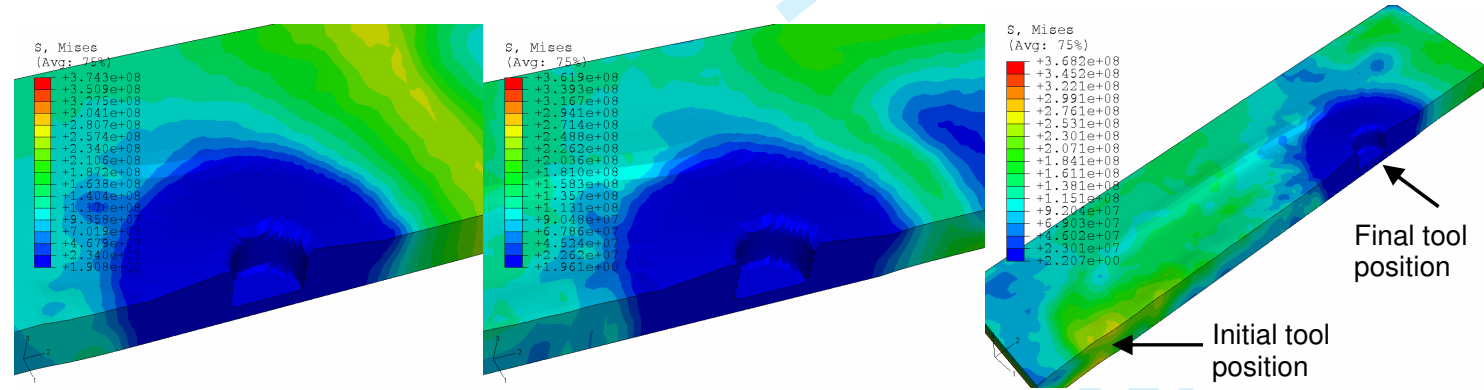

$10.4 s$

$15.4 \mathrm{~s}$

$22.4 \mathrm{~s}$

Figure 6. Von Mises stress plots $(\mathrm{N} / \mathrm{m} 2)$ at time $=0.4,1.0,3.0,6.6,7.1,8.3,10.4,15.4$ and 22.4 seconds. 


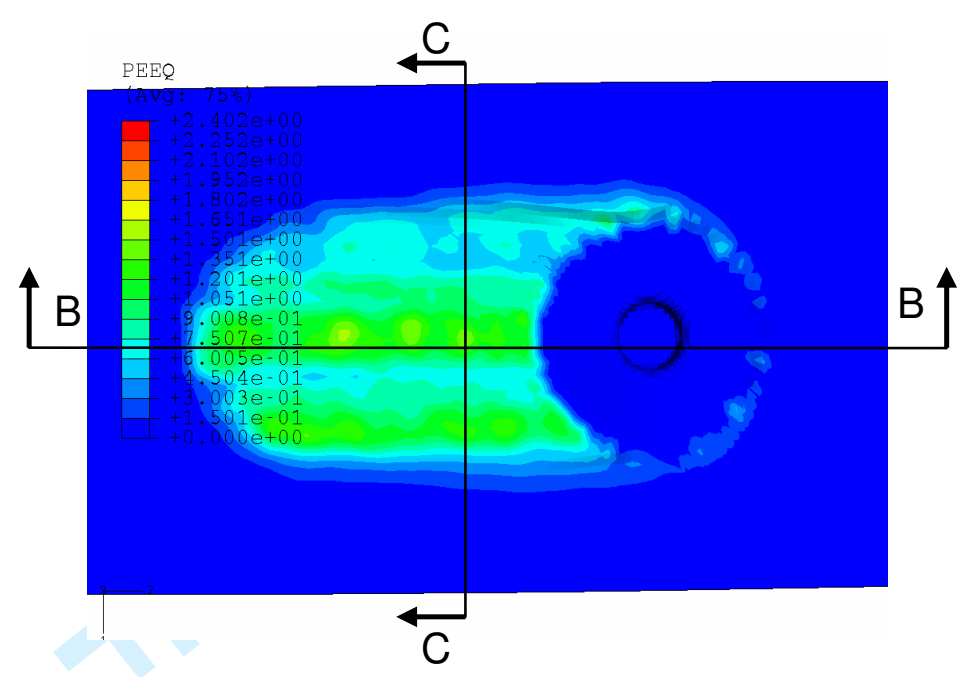

Top view

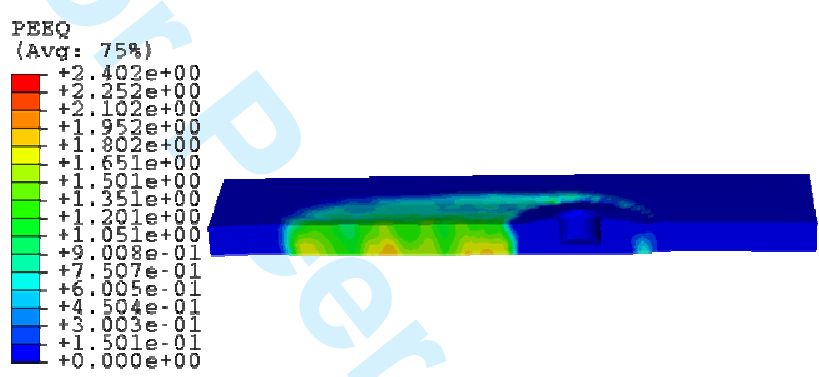

Longitudinal cross-section view (Section BB)

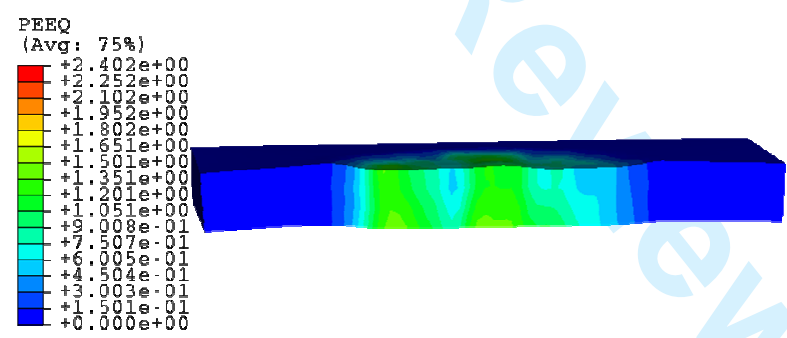

Transverse cross-section view (Section CC)

Figure 7. Equivalent plastic strain contour plots at 13.4s. 


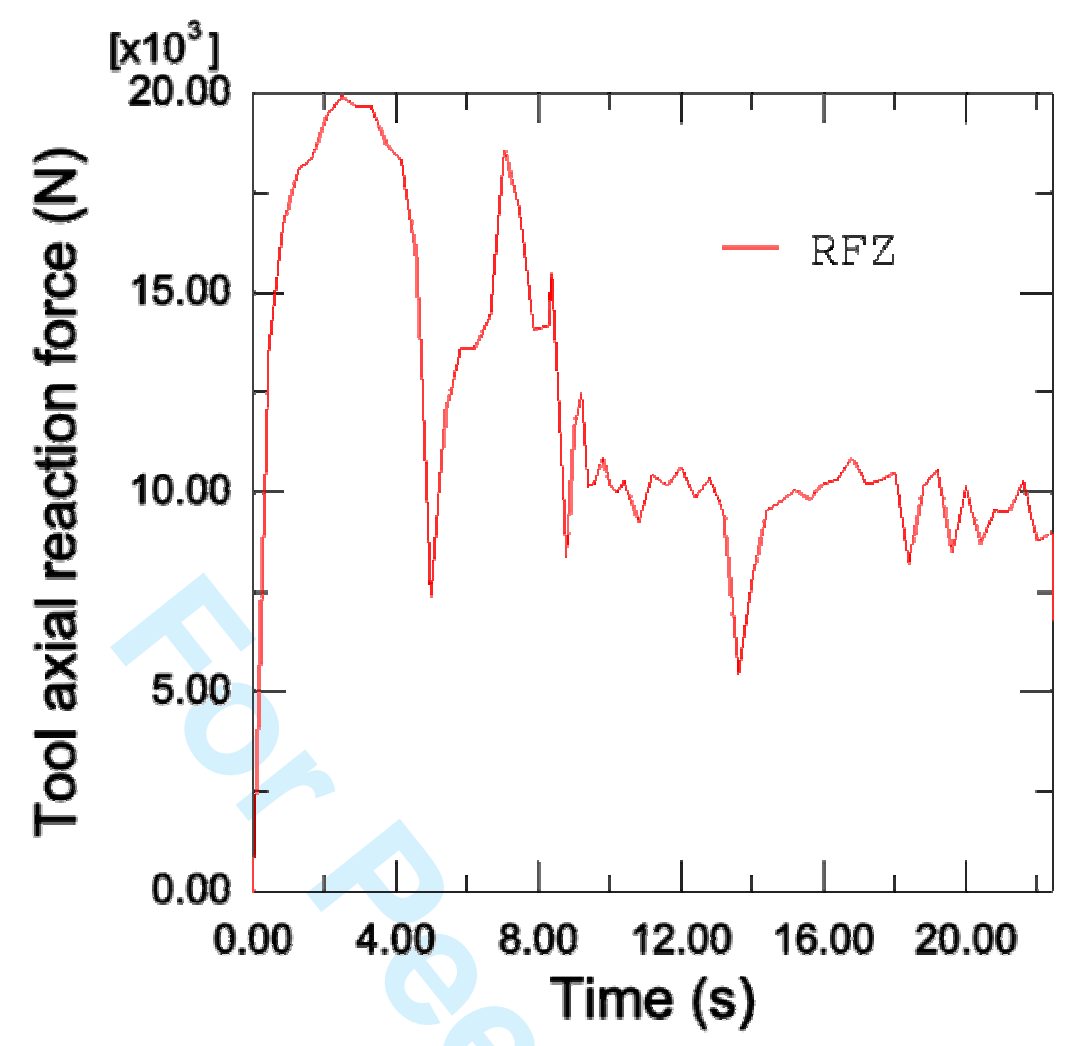

Figure 8. Tool reaction axial (z) force against time plot during the whole FSW process. 


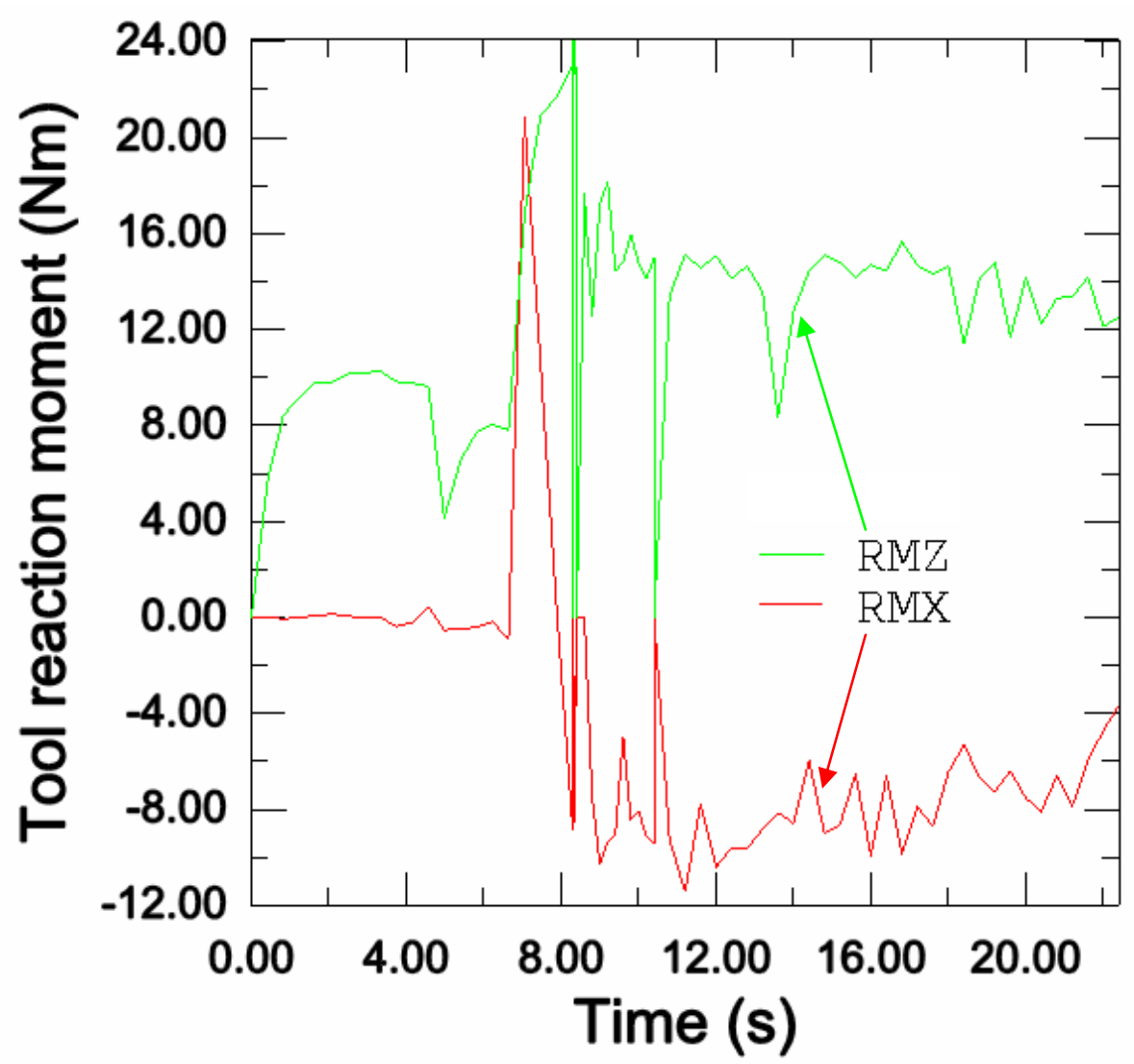

Figure 9. Tool reaction moments against time plot during the whole FSW process. 


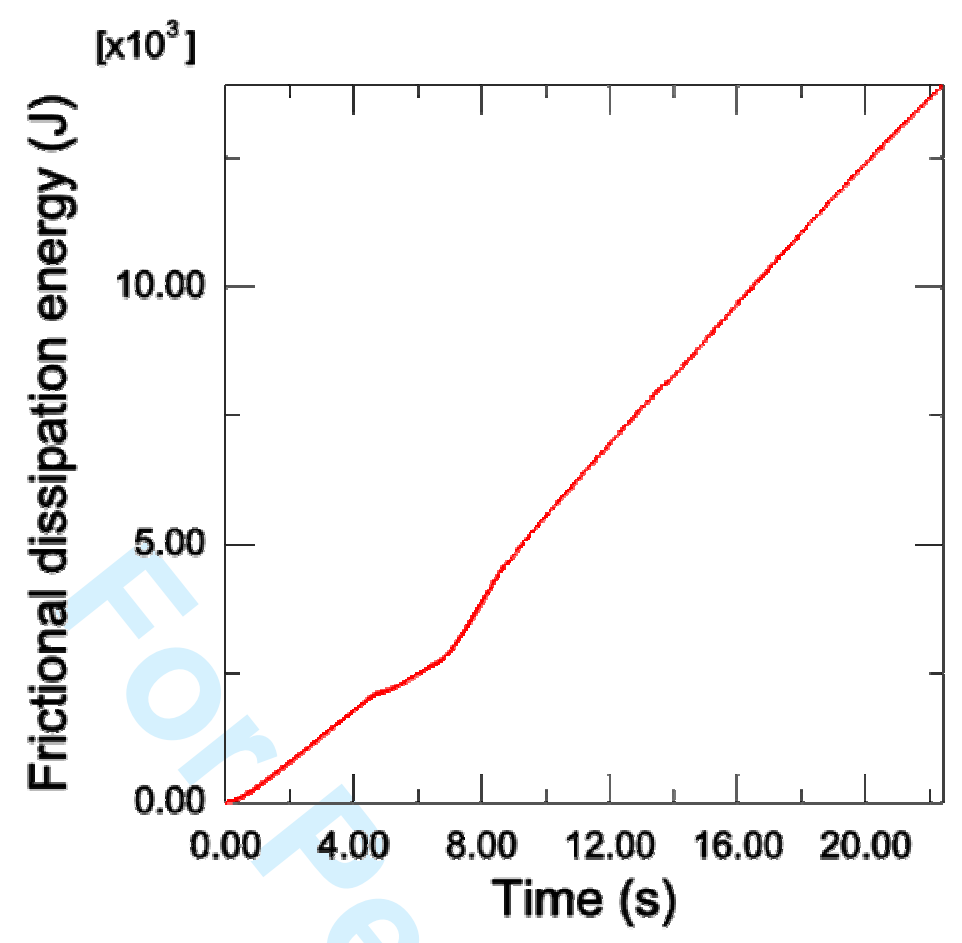

Figure 10. Frictional heat generation history. 


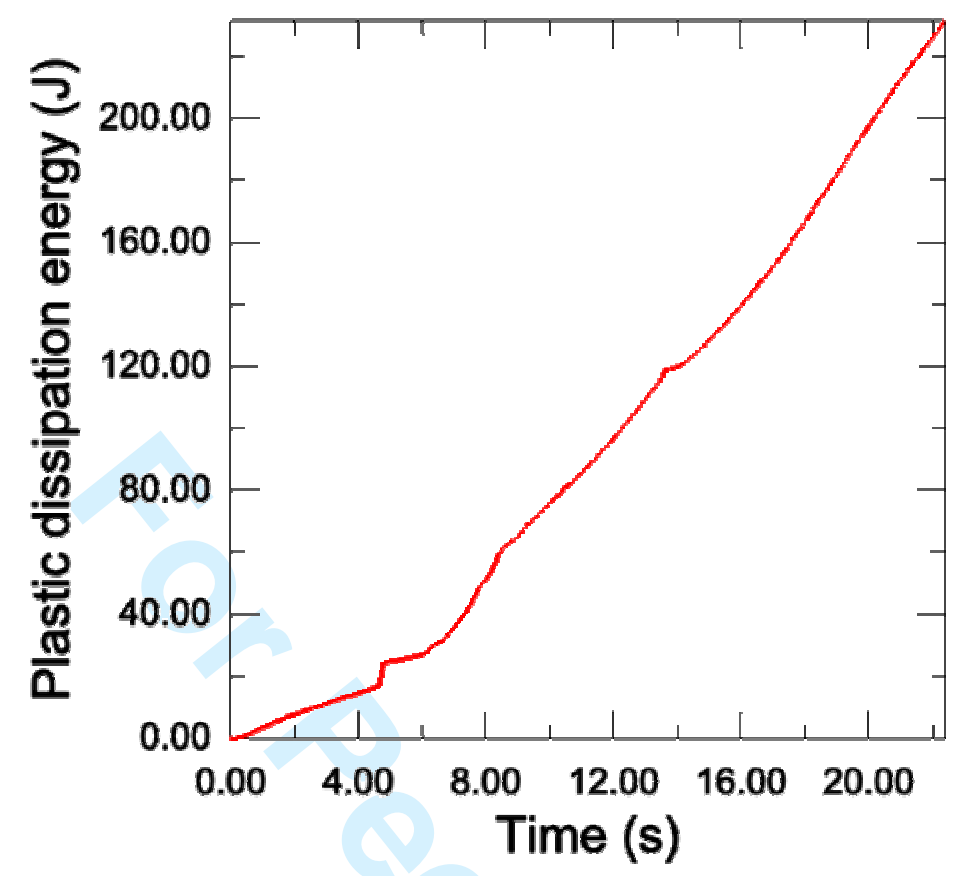

Figure 11. Plastic deformation heat generation history. 


1
2
3
4
5
6
7
8
9
10
11
12
13
14
15
16
17
18
19
20
21
22
23
24
25
26
27
28
29
30
31
32
33
34
35
36
37
38
39
40
41
42
43
44
45
46
47
48
49
50
51
52
53
54
55
56
57
58
59
60

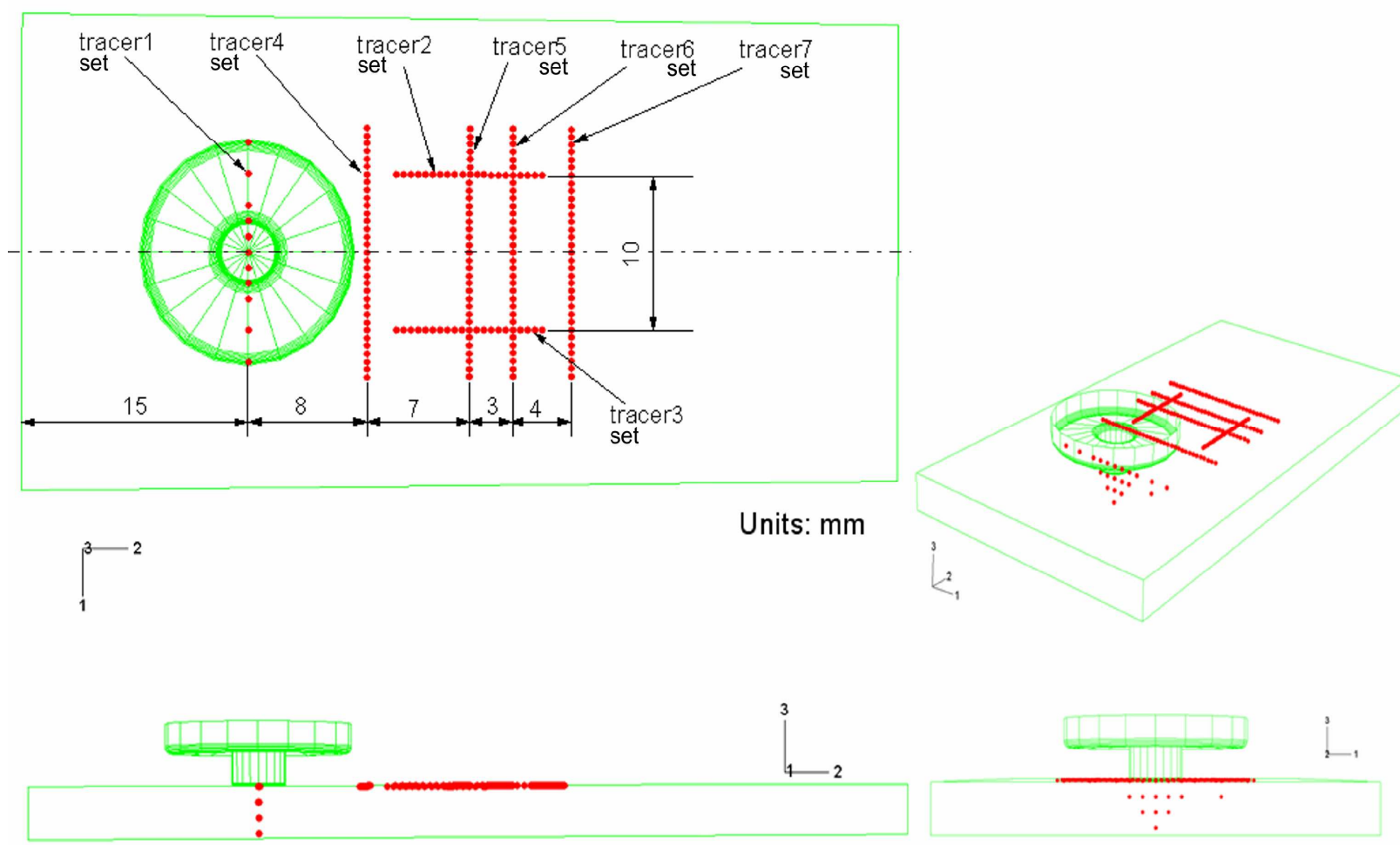

Figure 12. Original locations of defined tracer particle sets. 


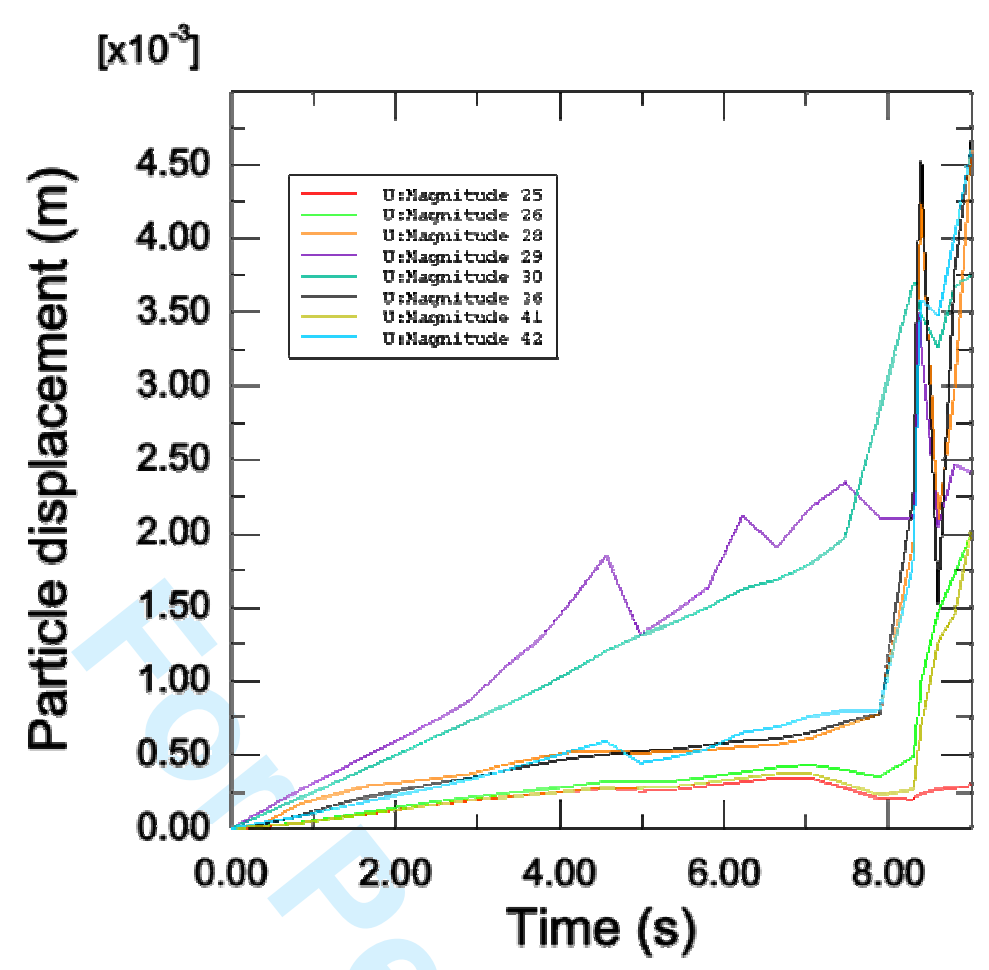

Figure 13. Displacement magnitudes for selected particles in tracer particle set "tracer1" from 9 to 15 seconds. 


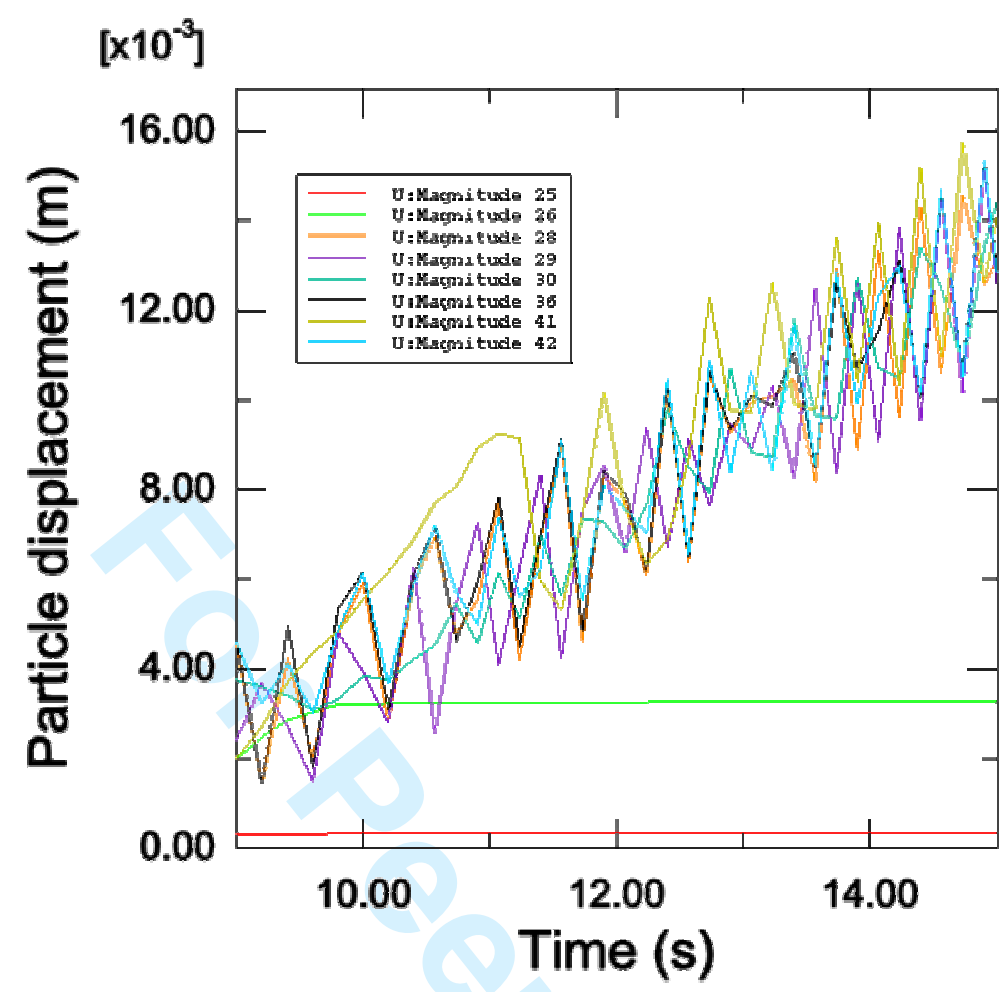

Figure 14. Displacement magnitudes for selected particles in tracer particle set "tracer1" from the start of the process up to 9 seconds. 


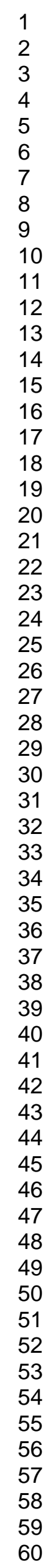

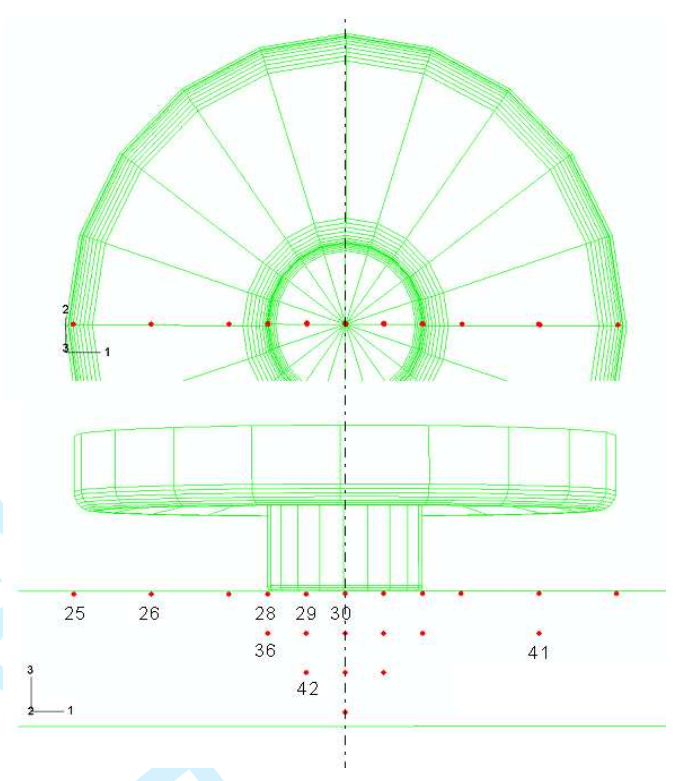

Figure 15. Positions of tracer particles of tracer1 at 0 s. 


1
2
3
4
5
6
7
8
9
10
11
12
13
14
15
16
17
18
19
20
21
22
23
24
25
26
27
28
29
30
31
32
33
34
35
36
37
38
39
40
41
42
43
44
45
46
47
48
49
50
51
52
53
54
55
56
57
58
59
60

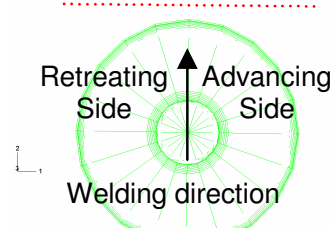

$8.3 \mathrm{~s}$

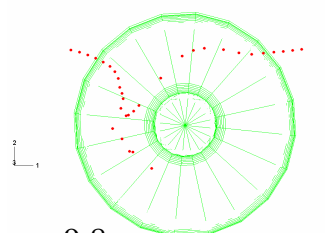

$9.8 \mathrm{~s}$
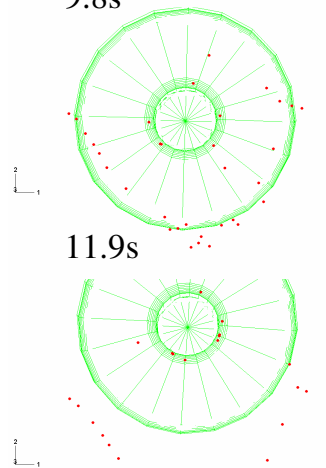

$14.4 \mathrm{~s}$
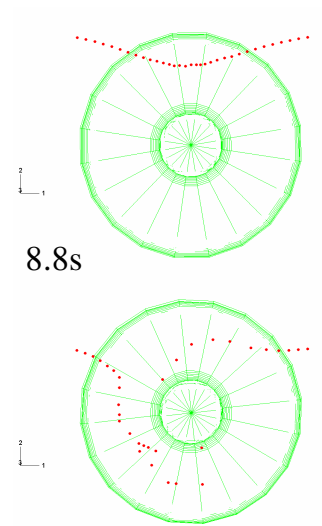

$10.2 \mathrm{~s}$

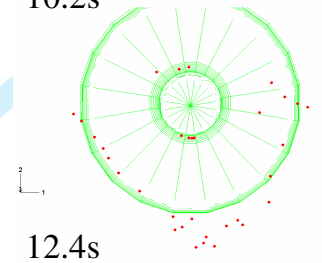

$12.4 \mathrm{~s}$

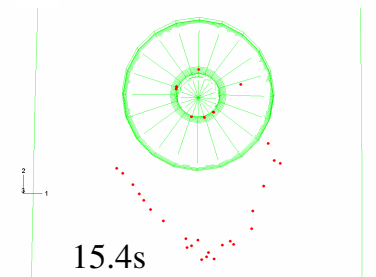

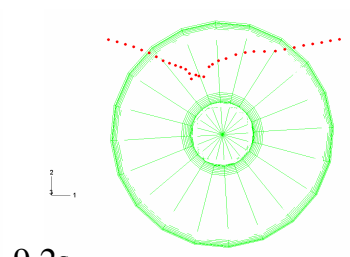

$9.2 \mathrm{~s}$

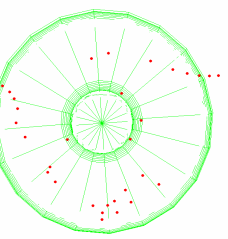

$10.7 \mathrm{~s}$

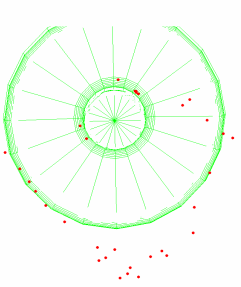

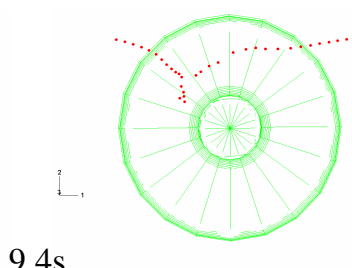

$9.4 \mathrm{~s}$

$11.2 \mathrm{~s}$

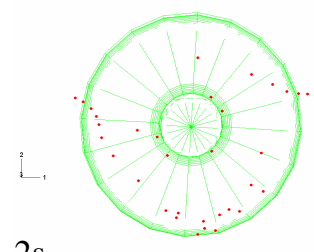

$11.2 \mathrm{~s}$

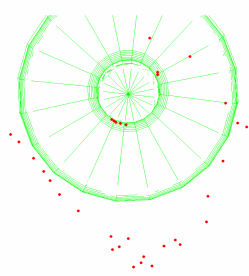

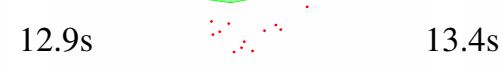

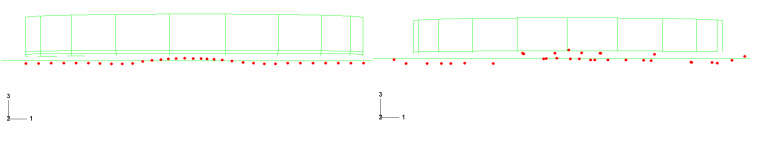

$8.8 \mathrm{~s}$

$15.4 \mathrm{~s}$

Figure 16. Positions of tracer particles, tracer4, at different time points. 


1
2
3
4
5
6
7
8
9
10
11
12
13
14
15
16
17
18
19
20
21
22
23
24
25
26
27
28
29
30
31
32
33
34
35
36
37
38
39
40
41
42
43
44
45
46
47
48
49
50
51
52
53
54
55
56
57
58
60
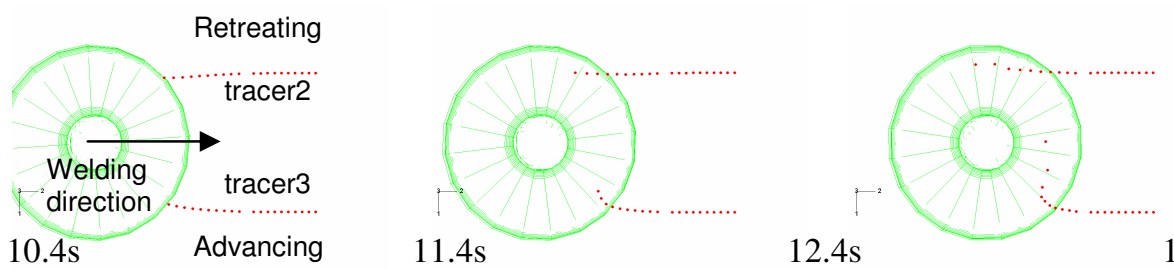

$12.4 \mathrm{~s}$

$12.9 \mathrm{~s}$
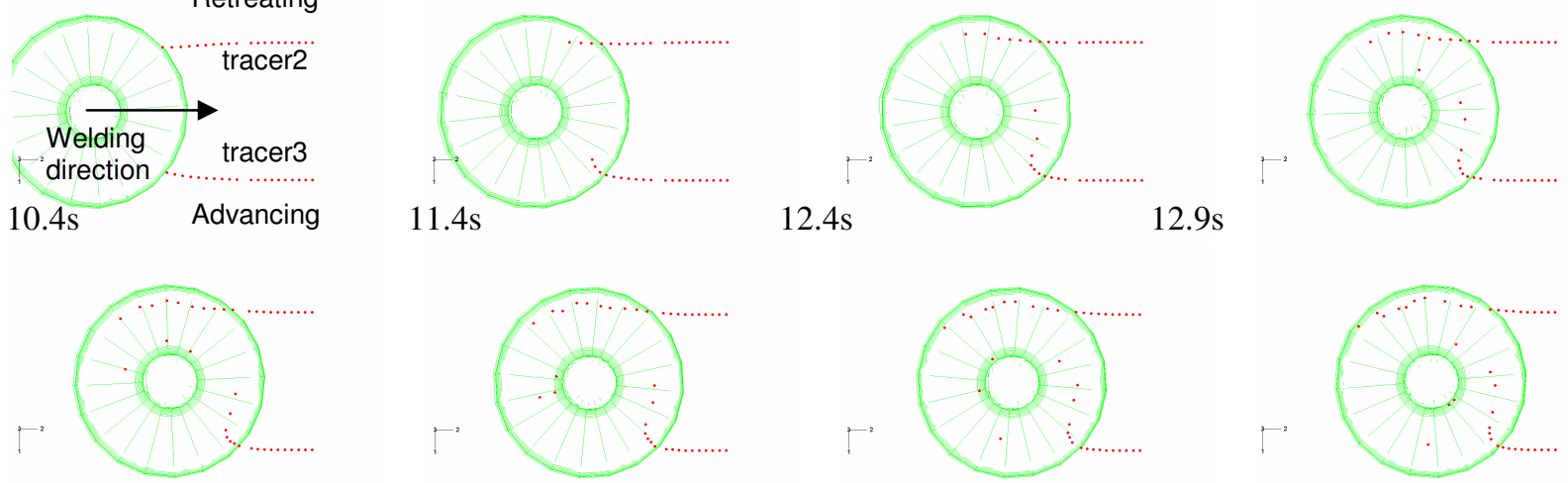

$13.2 \mathrm{~s}$

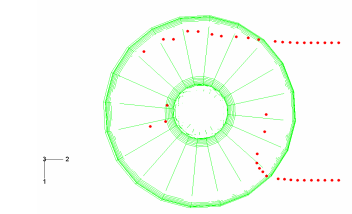

$13.4 \mathrm{~s}$

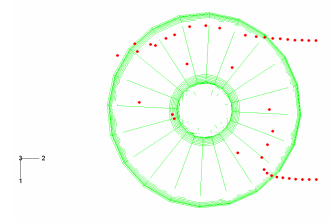

$14.4 \mathrm{~s}$

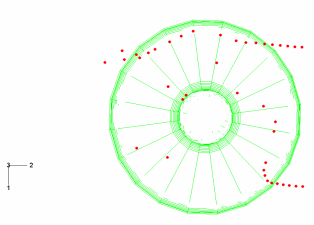

$14.9 \mathrm{~s}$

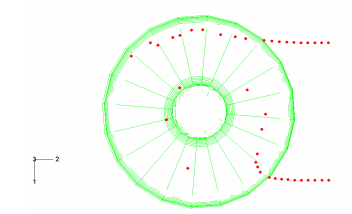

$13.7 \mathrm{~s}$

$13.9 \mathrm{~s}$
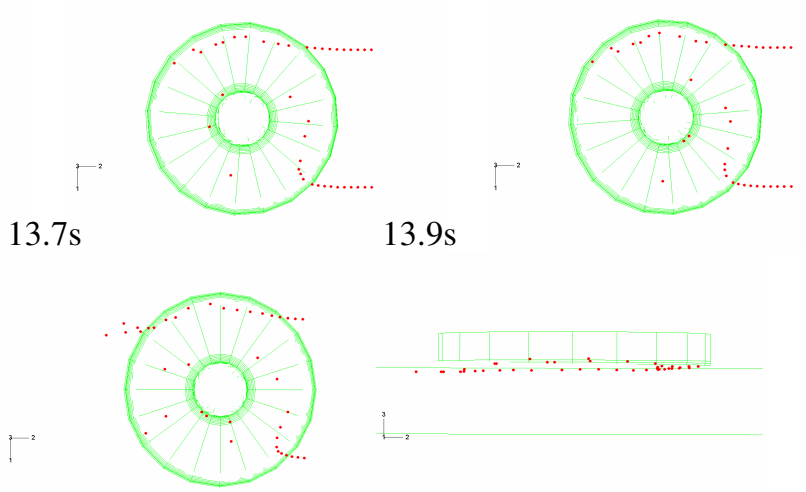

$15.4 \mathrm{~s}$

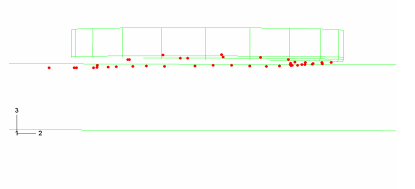

$15.4 \mathrm{~s}$

Figure 17. Positions of tracer particles, tracer2 and tracer3, at different time points. 